\title{
High copy numbers and $N$ terminal insertion position of influenza $A$ M2E fused with hepatitis B core antigen enhanced immunogenicity
}

\author{
Xincheng Sun ${ }^{1,2}$, Yunlong Wang ${ }^{1,3,4, *}$, Caiwen Dong ${ }^{2}$, Jinqiang Hu ${ }^{2}$, Liping Yang ${ }^{5}$ \\ 'Basic Medical School of Zhengzhou University, Zhengzhou, Henan, China, \\ ${ }^{2}$ College of Food and Biological Engineering, Zhengzhou University of Light Industry, Zhengzhou, Henan, China; \\ ${ }^{3}$ Bioengineering Research Center of Henan Province, Zhengzhou, Henan, China; \\ ${ }^{4}$ Henan Biotechnology Research Centre, Zhengzhou, Henan, China; \\ ${ }^{5}$ Basic Medical School of Henan University of Traditional Chinese Medicine, Zhengzhou, Henan, China.
}

\begin{abstract}
Summary
The extra domain of influenza M2 protein (M2e) is almost completely conserved among all influenza A virus subtypes. M2e is a promising candidate target for the development of a broad-spectrum recombinant influenza A vaccine. However, the immunogenicity of M2e needs to be improved. Copy numbers of M2e and its fusion expression with different carrier proteins may affect its immunopotency. In this study, we designed and created different constructs through genetic fusion of M2e (MSLLTEVETPTRSEWECRCSDSSD) (A/California/05/2009 (H1N1)) with the N-terminus (HBcAg1-149aa+Cys) by insertion in the $\mathrm{N}$-terminus Hepatitis B Core (HBc) antigen 1-149aa and Middle 78-81aa of HBcAg1-149aa to construct a recombinant M2e-based vaccine candidate. These chimeric sequences were expressed in Escherichia coli. We constructed fusion proteins containing influenza A H1N1 influenza virus (2009), as well as one, two, and three copies of M2e and hepatitis B core antigen1-149aa amino acid-optimized codon inserted $\mathbf{N}$ and its intermediate. The recombinant protein was expressed and purified. Western blot analysis was employed to evaluate the expression of the M2e recombinant protein containing different copy numbers of M2e. Mice were immunized for two times with the purified fusion protein $\mathrm{HBc} / \mathrm{M} 2 \mathrm{e}$ BALB/c. Serum levels of M2e antibody gradually increased along with increase in immunity. The levels of different fusion protein M2e antibodies increase with increasing M2e copy number. In addition, the protein antibody level in the $\mathbf{N}$ terminal fusion protein is higher than that in intermediate fusion.
\end{abstract}

Keywords: Influenza A (H1N1), M2e, HBc, vaccine

\section{Introduction}

Influenza is a common acute respiratory infectious disease in humans. Influenza epidemics result in millions of infections worldwide, including an estimated 250,000 to 500,000 deaths per year (1). The influenza virus is divided into three types (i.e., $\mathrm{A}, \mathrm{B}$, and $\mathrm{C}$ ) according to the antigenic difference of the viral nucleoprotein and the matrix protein. The vast majority of influenza cases are caused by the influenza virus types A or B. Influenza $\mathrm{C}$ seldom results in infection and pandemics (2).

\footnotetext{
*Address correspondence to:

Dr. Yunlong Wang, Basic Medical School of Zhengzhou University, 100 Science Avenue, Zhengzhou, Henan-450001, China.

E-mail: biowyl68@126.com
}

Vaccination is the most effective prophylaxes to control the spread of influenza. Influenza vaccine antigens (HA, NA), especially the HA antigen, can induce protective neutralizing antibodies and have a very important role in immunity. Given that the HA antigen often continues to mutate (including antigenic drift and shift), the choice of vaccine strain should also result in a corresponding change; otherwise, the vaccine prevention effect cannot be assured, even without much effect (2-4). Inactivated vaccines produced in embryonated hen eggs have several serious disadvantages (e.g., egg supply, matching vaccine strains, unwanted antigenic variants, and contamination with egg derived protein) that may decrease vaccine efficiency (5). Ideally, a flu vaccine should contain epitopes conserved in all influenza isolates to be effective against all strains of influenza $\mathrm{A}(6)$.

The influenza virus matrix protein 2 (M2) is the third 
outer membrane protein. The extracellular domain of M2 (M2e) contains 23 amino acids at the $\mathrm{N}$ end of influenza A virus M2 and is highly conserved in the influenza A virus, particularly in subtypes of human influenza A virus (7-8). At present, no significant difference has been found among the M2e proteins of all influenza A viruses in population prevalence. Antibodies specific to M2e can provide a cross-protective effect against different subtypes. Passive immunization with these antibodies has reduced viral replication in the lungs of mice infected with influenza A virus (9). Therefore, the development of a universal influenza vaccine that can provide crossprotective effect against different subtypes has attracted considerable research interest (10-12).

M2e is poorly immunogenic during natural infection (13). However, some approaches can be applied to enhance its immunogenicity. M2e has been linked to different carriers, including hepatitis B virus core $(\mathrm{HBc})$ $(14,15)$, TLR5 ligand flagellin (16), keyhole limpet hemocyanin (17), and virus-like particles (VLPs) (1820). These M2e-based vaccines could provide highly effective protection in animal models. Fusion proteins containing different copies of M2e epitope have demonstrated that high epitope density significantly enhances M2e-specific immunogenicity and protection (8). These studies have provided methods to enhance the immunogenicity of the M2e epitope. Nevertheless, studies on enhancing the immunogenicity of M2ebased vaccines in inducing better protective responses are important. Increasing epitope density enhances humoral immune response in systemic immunization. When M2e is linked to an appropriate carrier, such as $\mathrm{HBc}$ particles, the immunized mice achieve complete protection, which increases with the copy numbers of M2e epitope carried on the VLPs (21-23). However, regardless of epitope density, determining the effects of different M2e sequences, insertion position in the $\mathrm{HBcAg}$, and type of $\mathrm{HBcAg}$ on the level of antibodies and its immunopotency is necessary. The emergence of the new influenza virus A strain H1N1 originated form swine in the human population in 2009 has demonstrated the potential pandemic threat of influenza viruses (24).

In this study, we designed and created a number of different constructs through genetic fusion of M2e (MSLLTEVETPTRSEWECRCSDSSD) (A/ California/05/2009 (H1N1)) with the N-terminus and middle 78-81aa of (HBcAg1-149aa+Cys) by insertion in the immuno-dominant loop of $\mathrm{HBc}$ antigen (HBcAg1-149aa+Cys). These chimeric sequences were expressed in Escherichia coli, purified, and then analyzed as a recombinant fusion protein.

\section{Materials and Methods}

\subsection{PCR amplification and DNA cloning}

The fragment containing M2e (MSLLTEVETPTRSEWE

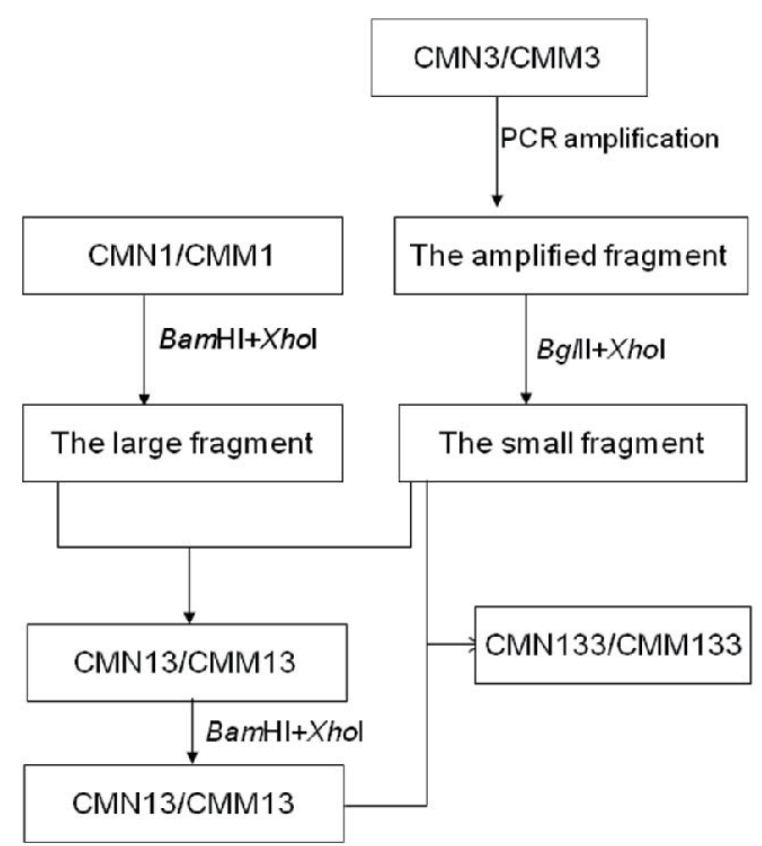

Figure 1. Contraction of the recombinant fusion gene.

CRCSDSSD 24 aa) gene and HBcAg1-149aa+Cys was amplified through PCR with the T7 primers from the CMM3/CMN3 plasmid, which carries the M2e gene from the influenza A virus (A/California/05/2009(H1N1)) and $\mathrm{HBcAg}(1-149 \mathrm{aa}+\mathrm{Cys})$ (Figure 1).

PCR was carried out in a $50 \mu \mathrm{L}$ reaction mixture containing $2 \times$ Pre-mix $(25 \mu \mathrm{L})$, specific primers $(10 \mathrm{pmol})$, $1.0 \mathrm{U}$ of pfu DNA polymerase (Takara Biotechnology (Dalian) Co., Ltd., China), and 100 ng of CMM3/CMN3 plasmid as template. Amplification program was set at $94^{\circ} \mathrm{C}$ for $5 \mathrm{~min}$, followed by 35 cycles at $94^{\circ} \mathrm{C}$ for 30 $\mathrm{s}, 53^{\circ} \mathrm{C}$ for $45 \mathrm{~s}, 72^{\circ} \mathrm{C}$ for $1 \mathrm{~min}$, and a final extension at $72^{\circ} \mathrm{C}$ for $5 \mathrm{~min}$. The resulting PCR products were analyzed using $1.0 \%(\mathrm{w} / \mathrm{v})$ agarose gel electrophoresis.

The amplified fragments, M2e and $\mathrm{HBcAg}(1-$ 149aa+Cys), were gel-purified using high purity PCR product purification kit (Roche, Germany) and digested with $B g l I I$ and $X h o I$ restriction enzymes. The fragments that underwent electrophoresis and gel-purification were named F-CMM3 and F-CMN3.

The pET30a-CMM1 and pET30a-CMN1 plasmid DNA were digested with BamHII and XhoI restriction enzymes, analyzed, and then gel-purified using the same methods as described above. The products were again gel-purified and ligated using T4 DNA ligase (Takara Biotechnology (Dalian) Co., Ltd., China) to form a recombinant vector named pET30a-CMM13/CMN13, which contains two copies of M2e. The pET30a-CMN13 and pET30a- CMM133 were identified using PCR (Figure 2).

The identified pET30a-CMN13 and pET30aCMM133 were digested with BamHII and XhoI restriction enzymes, analyzed, and the large fragment was gel-purified using the same method as described above. The digested and purified large fragments 


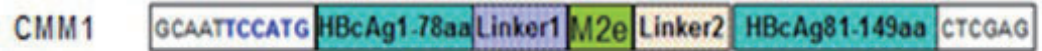

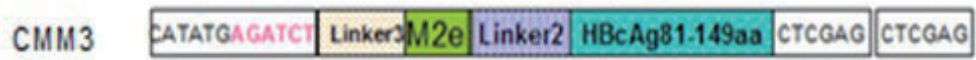

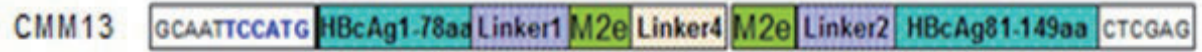

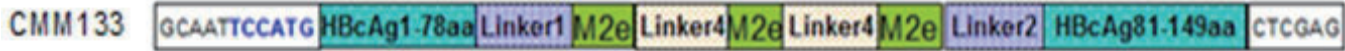

\begin{tabular}{ll|l|l|l|}
\hline CMN1 GCAATTCCATG & M2e Linker1 & HBcAg1-149+Cyc & CTCGAG \\
\hline
\end{tabular}

\begin{tabular}{|l|l|l|l|l|}
\hline CMN3 CATATGAGATCTLinker2 M2e Linker1 & HBcAg1-149+Cyc & CTCGAG \\
\hline
\end{tabular}

\begin{tabular}{ll|l|l|l|l|l|l|}
\hline CMN13 GCAATTCCATG & M2e Linker3 & M2e Linker1 & HBcAg1-149+Cyc & CTCGAG \\
\hline
\end{tabular}

\begin{tabular}{l|l|l|l|l|l|l|l|} 
CMN133 GCAATTCCATG & G2e Linker3 & M2e & Linker3 & M2e & Linker1 & HBcAg1-149+Cyc & CTCGAG \\
\hline
\end{tabular}

Bglll: AGATCT, Ndel: TCCATG, Xhol: CTCGAG ,BamHl: GGATCC

Figure 2. Schematic of the construction of M2e tandem copies.

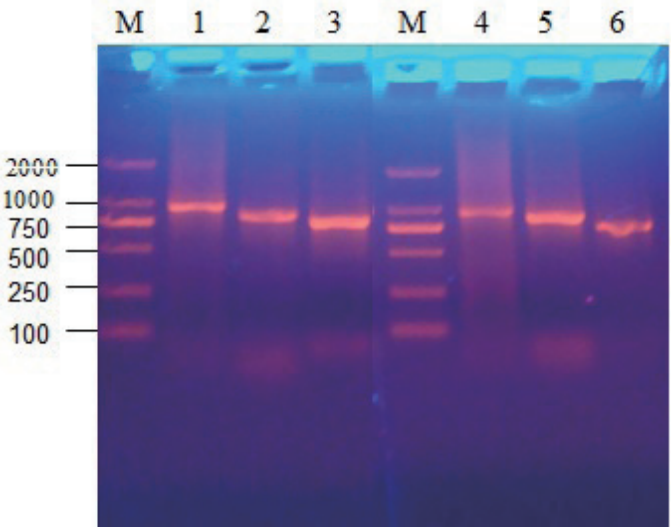

Figure 3. PCR analysis of the constructed CMN133 and CMM133 plasmid on $1.0 \%$ (w/v) agarose gel. M: DL2000 DNA Marker; 1: CMM133; 2: CMM13; 3: CMM1; 4: CMN133; 5: CMN13; 6: CMN1.

of pET30a-CMN13, F-CMM3, and F-CMN3 were respectively ligated using T4 DNA ligase to form recombinant vectors named pET30a-CMN133 and pET30a-CMN133, which contain three copies of M2e and one copy of $\mathrm{HBcAg}(1-149 \mathrm{aa}+\mathrm{Cys})$. The connected product was transformed to DH5a E. coli. The pET30aCMN133 and pET30a-CMM133 fragments were identified using PCR (Figure 3).

\subsection{Transformation of BL21 and selection of transformants}

Recombinant vectors were purified from the transformed cells under the selection of $30 \mathrm{mg} / \mathrm{mL}$ Kanamycin antibiotics (Takara Biotechnology (Dalian) Co., Ltd., China) and after the restriction analysis was confirmed using sequencing reaction.

2.3. Expression and purification of recombinant protein in BL21(DE3)

CMN1, CMM1, and CMN133CMN133 were respectively transformed into $\mathrm{BL} 21 \mathrm{E}$. coli. A single colony was picked and grown in $3.5 \mathrm{~mL} \mathrm{LB}$ supplemented with $30 \mathrm{mg} / \mathrm{mL}$ Kanamycin, and shaken for $16 \mathrm{~h}$ at $37^{\circ} \mathrm{C}$ and $200 \mathrm{rpm}$. A $500 \mu \mathrm{L}$ culture was added with $500 \mu \mathrm{L}$ of $15 \%(\mathrm{v} / \mathrm{v})$ sterile glycerol and stored at $20^{\circ} \mathrm{C}$. To express CMN1, CMM1, and CMN133CMN133, each tube $(35 \mu \mathrm{L})$ of glycerol stock was expanded to a starter culture of $3.5 \mathrm{~mL} \mathrm{LB}+\mathrm{Kana}$ and shaken overnight at $37^{\circ} \mathrm{C}$. The culture was then expanded to $1000 \mathrm{~mL} \mathrm{LB}+$ Kana induction, and grown to OD600 0.5 at $37^{\circ} \mathrm{C}$. Protein expression was induced with $30 \mu \mathrm{M}$ isopropyl $\beta$-D-1-thiogalactopyranoside (IPTG) for $6 \mathrm{~h}$. The culture medium $(1 \mathrm{~mL})$ was sampled for assessment of expression using sodium dodecyl sulfate polyacrylamide gel electrophoresis (SDS-PAGE).

The cells were harvested and re-suspended in a 300 $\mu \mathrm{L}$ of $0.05 \mathrm{M}$ PB buffer. After incubation, the cell wall was disrupted by ultrasonication (Branson sonifier 450) for $30 \mathrm{~min}$ at $250 \%$ to $300 \%, 550 \mathrm{~W}$, with $10 \mathrm{~s}$ pulses and $5 \mathrm{~s}$ pauses for each cycle; the entire process was executed on ice. The broken cells were centrifuged at $10,000 \mathrm{~g}$ for $20 \mathrm{~min}$ at $4^{\circ} \mathrm{C}$ to separate the soluble and insoluble proteins. The insoluble protein or inclusion body was dissolved in the denaturing solubilization buffer $\left(50 \mathrm{mM} \mathrm{NaH} \mathrm{PO}_{4}, 300 \mathrm{mM} \mathrm{NaCl}, 8 \mathrm{M}\right.$ urea, $\mathrm{pH}$ 8.0 ). The soluble protein and dissolved-inclusion body 
were analyzed using 12\% SDS-PAGE. The presence of tagged- $6 \times$ His fused recombinant protein was further confirmed using Western blot.

\subsection{Purification of fusion protein}

The recombinant protein CMN1, CMM1, and CMN133CMN133 with $6 \times$ His tagged at the $\mathrm{C}$-terminus was purified by affinity chromatography under denaturing conditions. A column containing $1 \mathrm{~g}$ of nickel sulfate was equilibrated with four bed volumes of denaturing solubilization buffer. The solubilizedinclusion body was diluted at a ratio of $1: 2$ in the denaturing solubilization buffer containing $20 \mathrm{mM}$ imidazole before being added into a column and being allowed to flow by gravity. The resin was washed thrice using four bed volumes of denaturing solubilization buffer containing $20 \mathrm{mM}$ imidazole and one bed volume of denaturing solubilization buffer containing $50 \mathrm{mM}$ imidazole. The recombinant CMN1, CMM1, and CMN133CMN133 were separated using 12\% SDSPAGE through a discontinuous Tris-glycine buffer system ( $\mathrm{pH} 8.3)$.

\subsection{SDS-PAGE and Western blot analysis}

Protein samples were separated using 12\% SDSPAGE. The gel was stained with Coomassie brilliant blue R-250 and a broad-range low molecular weight marker (Takara Biotechnology (Dalian) Co., Ltd., China) was used to estimate protein size. For Western blot analysis, separated proteins were transferred onto a polyvinylidene difluoride (PVDF) membrane using transfer buffer $(39 \mathrm{mmol} / \mathrm{L}$ glycine, $48 \mathrm{mmol} / \mathrm{L}$ Tris base, $0.037 \%$ SDS) and was incubated in the blocking buffer (0.01 M TBS pH 7.4, 3\% bovine serum albumin) for about $30 \mathrm{~min}$. Subsequently, the membrane was washed for five times with a washing buffer $(0.01 \mathrm{M}$ TBS pH7.4, 0.1\% Tween 20), and then with $\mathrm{ddH}_{2} \mathrm{O}$. The membrane was then probed with horse-radish peroxidase-conjugated anti-penta-His Ab (Sangon Biotech (shanghai) Co., Ltd., China) for $30 \mathrm{~min}$, and then washed again with washing buffer and deionized water. The PVDF membrane was dyed in the solution [30 mL of $\mathrm{ddH}_{2} \mathrm{O}, 200 \mu \mathrm{L}$ of $1.5 \mathrm{M}$ Tris base (pH8.8), $200 \mu \mathrm{L}$ of $1.0 \mathrm{M}$ Tris base (pH 6.8), $200 \mu \mathrm{L}$ of $\mathrm{NiSO}_{4}$, $100 \mu \mathrm{L}$ of $\mathrm{H}_{2} \mathrm{O}_{2}$, and $10 \mathrm{mg}$ of diaminobenzidine (DAB)]. Protein bands were revealed by their exposure to substrate DAB (Sangon Biotech (shanghai) Co., Ltd., China).

\subsection{Immunization}

Female Balb/C mice (45 day-old) were intraperitoneally immunized with CMN1, CMN133, CMM1, and CMM133 (100 $\mu \mathrm{g} /$ per mouse) in incomplete Freund's adjuvant, aluminum adjuvant, or PBS at a final volume of $200 \mu \mathrm{L}$. The animals were randomly divided into five groups (i.e., PBS, CMN1, CMN133, CMM1, and CMM133), with 10 mice in each group. A booster immunization was administered with the same immunogen after two weeks. Sera were collected 14 days after final immunization. Two immunizations were administered two weeks apart.

\subsection{Antibody detection}

The M2e-specific antibodies were detected using enzyme-linked immunosorbent assay (ELISA). Briefly, 96-well microtiter plates were coated with 50 $\mu \mathrm{L}$ of M2e peptide $(5 \mu \mathrm{g} / \mathrm{mL})$ in PBS for $2 \mathrm{~h}$ at room temperature and blocked with PBS containing $0.25 \%$ gelatin. Serum samples were serially diluted and added, followed by $1 \mathrm{~h}$ of incubation at room temperature. After extensive washes, the bound antibodies were detected sequentially by adding 1:2,000 diluted horseradish peroxidase-linked anti-mouse antibodies and substrate o-phenylenediamine dihydrochloride peroxide solution (Sangon Biotech (shanghai) Co., Ltd., China). Absorbance at $450 \mathrm{~nm}$ was recorded.

Identification of the isotypes of M2e-specific antibodies was carried out as previously described (25).

\section{Results}

\subsection{Construction of recombinant fusion plasmid, pCMN133}

Influenza A virus M2e and $\mathrm{HBc}$ (HBcAg1-149aa+Cys) fusion genes were PCR amplified using T7 sequence primers from pET30a CMN3 plasmid. The purified fusion genes (named FM2EHBV) and pET30a CMN1 were digested, purified, and combined to form the fusion gene, pET30a-CMN13, which encoded two copies of M2e and HBcAg1-149aa+Cys protein in a single open reading frame (ORF). FM2EHBV digested with $B g l$ II and $X h o I$ restriction enzymes and the purified large fragment of pET30a-CMN13 digested with BamHI and XhoI were combined to form the fusion gene pET30a-CMN13 3, which encoded three copies M2e and HBcAg1-149aa+Cys protein in a single ORF (Figure 2).

Cloning of three copies of M2e-HBcAg1-149aa+Cys sequence into the multiple cloning site of pET30 plasmid resulted in the expression of a larger fusion protein that contained His-tag and -linker (9aa: GGGGSGGGG).

\subsection{Expression, purification, and confirmation of recombinant M2e-HBc fusion protein}

$\mathrm{M} 2 \mathrm{e}-\mathrm{HBc} / 6 \times \mathrm{His}$ gene in $E$. coli cells was confirmed using PCR and gene-specific primers. Several confirmed colonies were further induced for expression of the fusion protein under the direction of a Lac 


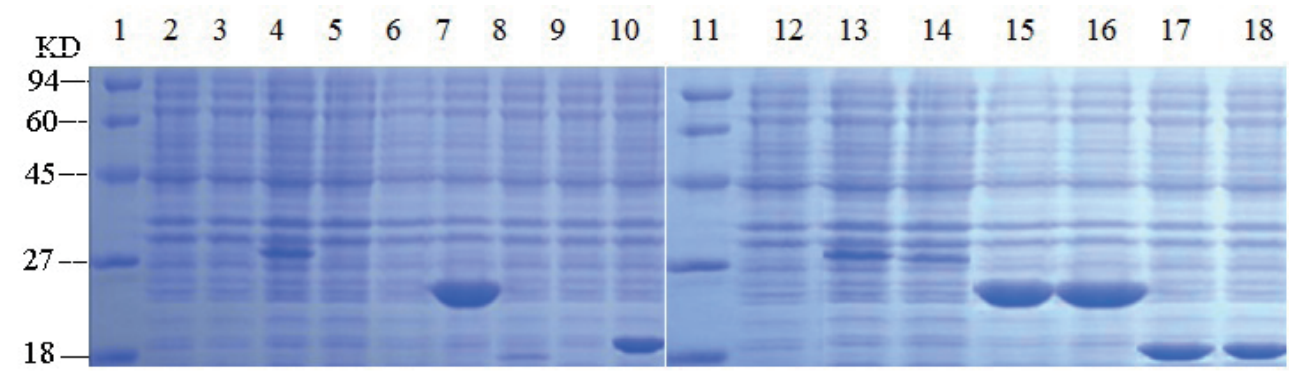

Figure 4. Analysis of recombinant M2e HBV/6 $\times$ His fusion protein in the culture media by SDS-PAGE. Lane 1: Marker. Lane 2: Sample from CMN133 E. coli prior to IPTG induction. Lane 3: Supernatant from CMN133 E. coli after 4 h of IPTG induction. Lane 4: Sediment of from CMN133 after $4 \mathrm{~h}$ of IPTG induction. Lane 5: Sample from CMN13 E. coli prior to IPTG induction. Lane 6: Supernatant from CMN13 E. coli after $4 \mathrm{~h}$ of IPTG induction. Lane 7: Sediment from CMN13 E. coli after $4 \mathrm{~h}$ of IPTG induction. Lane 8: Sample from CMN1 E. coli prior to IPTG induction. Lane 9: Supernatant from CMN1 E. coli after $4 \mathrm{~h}$ of IPTG induction. Lane 10: Sediment from CMN1 E. coli after 4 h of IPTG induction. Lane 11: Marker. Lane12: Sample from BL21 (DE3). Lane 13: Supernatant from CMM133 after $4 \mathrm{~h}$ of IPTG induction. Lane 14: Sediment from CMM133 after $4 \mathrm{~h}$ of IPTG induction. Lane 15: Supernatant of from CMM13 after $4 \mathrm{~h}$ of IPTG induction. Lane 16: Sediment from CMM13 after $4 \mathrm{~h}$ of IPTG induction. Lane 17: Supernatant from CMM1 after $4 \mathrm{~h}$ of IPTG induction. Lane 18: Sediment from CMM1 after $4 \mathrm{~h}$ of IPTG induction.

promoter by adding IPTG. The culture was sampled after being induced for $4 \mathrm{~h}$ for the final analysis using SDS-PAGE. As illustrated in Figure 4, a protein band corresponding to the expression of the recombinant fusion protein with an approximate molecular weight of $30 \mathrm{kDa}$ was detected in all three samples, but was absent in the uninduced cells. However, the recombinant protein expression was slightly higher. Moreover, the fusion of vector-derived $6 \times$ His tag to the C-terminus of the expressed protein provided the possibility of its one-step purification through the NiNTA columns (Figure 4).

\subsection{Confirmation of the recombinant M2e-HBc fusion protein}

To confirm the purified protein, the purified recombinant proteins CMN1, CMN133, CMM1, and CMM133 were transferred to a PVDF membrane and treated with M2e monoclonal antibody. A band with the expected size $(23$ and $30 \mathrm{kDa}$ ) was revealed in the lane of the purified protein, which corroborated its accuracy, as shown in Figure 5. A single copy and three copies of the protein were successfully expressed and had the antigenicity of M2e.

\subsection{ELISA result}

To detect four kinds of purified protein using ELISA, the purified single copy and three copies of the fusion protein were coated and detected using anti M2e monoclonal antibody preparation, with four kinds of fusion proteins from 1:10,000, 1:20,000, 1:40,000, $1: 80,000$, and 1:160,000. The results (Figure 6) showed that the fusion protein in dilution 1:40,000 were active, and that a single copy of the fusion protein exhibited activity below three copies of protein. The three copies of protein in the $\mathrm{N}$-terminus fusion protein were slightly higher than that in the middle of the insertion of the $\mathrm{HBc}$ antigen protein.

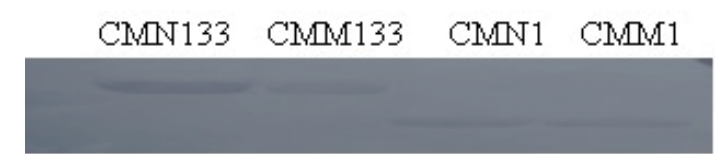

Figure 5. Western blot of the purified recombinant protein.

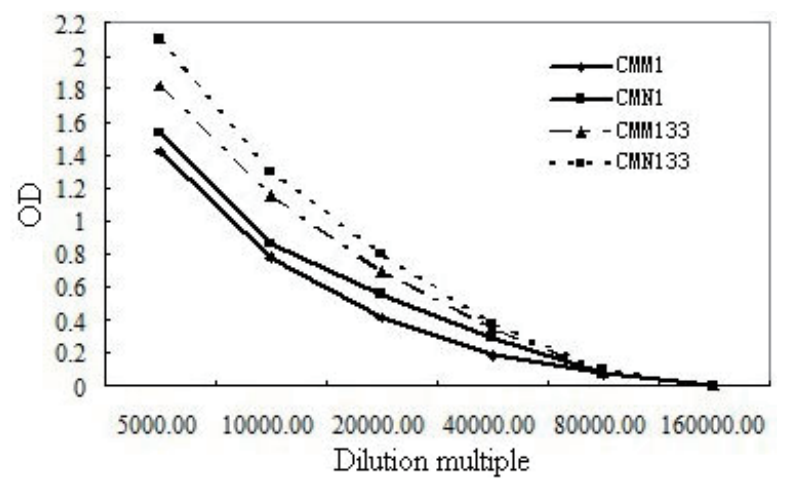

Figure 6. ELISA detection of M2e.

\subsection{Detection of serum titer of mice}

The titer of the serum anti-M2e antibody was detected using indirect ELISA two weeks after each immunization and before the final immunization. This was executed after the mice have been immunized with purified single copy and three copies of M2e protein. The experimental results showed that the CMN1, CMN133, CMM1, and CMM133 groups could produce anti M2eIgG antibody in the induced mice. The antibody titer increased with the number of strengthening immunity. The three copies of M2e were significantly better than the single copy at two weeks after the first immunization. No significant differences were observed between CMN1 and CMM1 and CMM133 and CMN133. Alternatively, significant differences were observed among the antibody titer of CMN1, CMM1, CMN133, and CMM133 at four weeks after the final immunization (Figure 7). 


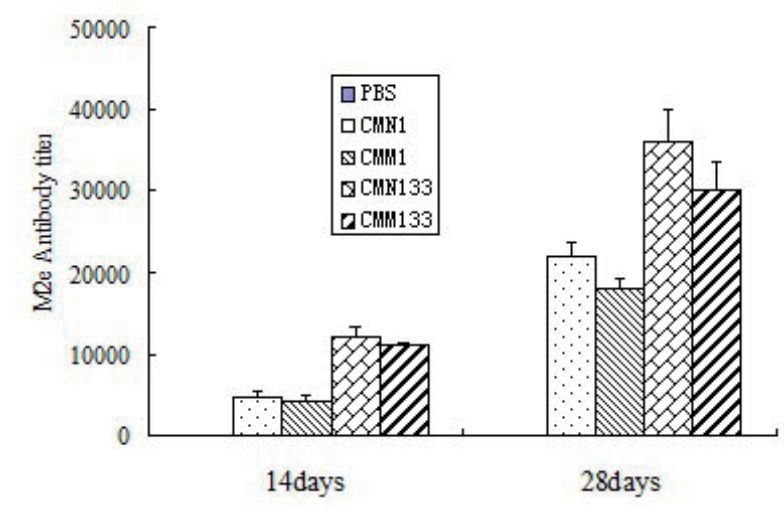

Figure 7. Detection result of serum titer of mice.

\section{Discussion}

M2e-based universal influenza vaccines have attracted research interest because of the highly conservative character of the sequence of M2e membrane protein in all influenza A isolates (20). Results of several preclinical studies with M2e protein, with or without carriers, have already proven the successful protection of M2e-based vaccinated animal models against the lethal challenge of heterologous and homologous influenza A virus.

$\mathrm{HBc}$ particles have been used as virus-like display scaffolds since 1980s (26). In the last 30 years, the most successful application of this scaffold is the influenza vaccine ACAM-FLU-A produced by Sanofi Pasteur and the malaria (Plasmodium falciparum) vaccine MalariVax (ICC-1132) produced by Apovia $(27,28)$. These particles have been expressed in E. coli with the $\mathrm{HBc}$ as the foreign insertion site, and they have already been subjected to phase I clinical trials.

However, the M2e-based immunization effect against influenza virus differs under various conditions of expression strategy, immune pathway, and animal model. Host-specific variations were also observed in M2e sequences among influenza strains from different hosts. Thus, evaluating whether M2e-based immunization could provide protection against the 2009 pandemic $\mathrm{H} 1 \mathrm{~N} 1$ is necessary.

In this study, we successfully constructed the aforementioned plasmids bearing one copy, three copies of M2e, and HBc (HbcAg1-149aa+Cys). These fusion proteins were expressed in E. coli. Considering the senior conformation and structural features of M2 protein, the linker arm of GGGGSGGGG in the fusion proteins was located between $\mathrm{M} 2 \mathrm{e}$ and $\mathrm{HBc}$ ( $\mathrm{HBcAg} 1-$ $149 \mathrm{a}+\mathrm{Cys})$. A single cysteine residue was added to the C-terminus to provide additional stabilization (29). All of the purified proteins of CMN1, CMM1, CMN133, and CMM133 in incomplete Freund's adjuvant can induce production of IgG antibody against M2e. Higher epitope density engendered higher antibody levels. The ELISA showed that the increase in M2e copies results in an increase in level of the immune serum antibody. The insertion position of $\mathrm{M} 2 \mathrm{e}$ in the $\mathrm{HBc}$ affects the antibody level.

In conclusion, our study provided evidence for the construction of the M2e-HBcAg1-149aa+Cys fusion sequence. The sequence had been successfully expressed in E. coli, and the purified protein induced the production of antibodies against M2e. These fusion proteins are potential candidates for developing influenza vaccine. However, further investigation is necessary to evaluate the in vivo protective potential of the resulting protein.

\section{Acknowledgements}

This work was supported by a grant from the key scientific and technological research project of Henan Province (142102310062) and scientific and technological research project of Zhengzhou City (141PPTGG347).

\section{References}

1. Ryan J, Zoellner Y, Gradl B, Palache B, Medema J. Establishing the health and economic impact of influenza vaccination within the European Union 25 countries. Vaccine. 2006; 24:6812-6822.

2. Palese P. Influenza: Old and new threats. Nat Med. 2004; 10:82-87.

3. Scalera NM, Mossad SB. The first pandemic of the 21st century: A review of the 2009 pandemic variant influenza A (H1N1) virus. Postgrad Med. 2009; 5:43-47.

4. Kilbourne ED. Influenza pandemics of the 20th century. Emerg Infect Dis. 2006; 12:9-14.

5. Subbarao K, Matsuoka Y. The prospects and challenges of universal vaccines for influenza. Trends Microbiol. 2013; 21:350-358.

6. Denis J, Acosta-Ramirez E, Zhao Y, Block T M, Gish R, Guo H, Mehta A, Cuconati A, Thomas London W, Guo JT. Chronic hepatitis B: What should be the goal for new therapies. Antiviral Res. 2013; 98:27-34.

7. De Filette M, Fiers W, Martens W, Birkett A, Ramne A, Löwenadler B, Lycke N, Jou WM, Saelens X. Improved design and intranasal delivery of an M2e-based human influenza A vaccine. Vaccine. 2006; 24:6597-6601.

8. Liu W, Zou P, Ding J, Lu Y, Chen YH. Sequence comparison between the extracellular domain of M2 protein human and avian influenza A virus provides new information for bivalent influenza vaccine design. Microbes Infect. 2005; 7:171-177.

9. Turley CB, Rupp RE, Johnson C, Taylor DN, Wolfson J, Tussey L, Kavita U, Stanberry L, Shaw A. Safety and immunogenicity of a recombinant M2e-flagellin influenza vaccine (STF2.4xM2e) in healthy adults. Vaccine. 2011; 29:5145-5152.

10. Ebrahimi SM, Tebianian M. Influenza A viruses: Why focusing on M2e-based universal vaccines. Virus Genes. 2011; 42:1-8.

11. De Filette M, Martens W, Smet A, Schotsaert M, Birkett A, Londoño-Arcila P, Fiers W, Saelens X. Universal influenza A M2e-HBc vaccine protects against disease 
even in the presence of pre-existing anti-HBc antibodies. Vaccine. 2008; 26:6503-6507.

12. Subbarao K, Matsuoka Y. The prospects and challenges of universal vaccines for influenza. Trends Microbiol. 2013; 7:350-358.

13. Feng J, Zhang M, Mozdzanowska K, Zharikova D, Hoff H, Wunner W, Couch RB, Gerhard W. Influenza A virus infection engenders a poor antibody response against the ectodomain of matrix protein 2. Virol J. 2006; 3:102.

14. Blokhina EA, Kuprianov VV, Stepanova LA, Tsybalova LM, Kiselev OI, Ravin NV, Skryabin KG. A molecular assembly system for presentation of antigens on the surface of HBc virus-like particles. Virology. 2013; 20:293-300.

15. Arora U, Tyagi P, Swaminathan S, Khanna N. Virus-like particles displaying envelope domain III of dengue virus type 2 induce virus-specific antibody response in mice. Vaccine. 2013; 31:873-878.

16. Talbot HK, Rock MT, Johnson C, Tussey L, Kavita U, Shanker A, Shaw AR, Taylor DN. Immunopotentiation of trivalent influenza vaccine when given with VAX102, a recombinant influenza M2e vaccine fused to the TLR5 ligand flagellin. PLoS One. 2010; 5:e14442.

17. Reese KA, Lupfer C, Johnson RC, Mitev GM, Mullen VM, Geller BL, Pastey M. A novel lactococcal vaccine expressing a peptide from the M2 antigen of $\mathrm{H} 5 \mathrm{~N} 2$ highly pathogenic avian influenza A virus prolongs survival of vaccinated chickens. Vet Med Int. 2013; 5:1-8.

18. Kim MC, Lee YN, wang HS, Lee YT, Jung YJ, Cho MK, Kim YJ, Lee JS, Ha SH, Kang SM. Influenza M2 viruslike particles confer a broader range of cross protection to the strain-specific pre-existing immunity. Vaccine. 2014; 32:5824-5831.

19. Wang L, Hess A, Chang TZ, Wang YC, Champion JA, Compans RW, Wang BZ. Nanoclusters self-assembled from conformation-stabilized influenza M2e as broadly cross- protective influenzavaccines. Nanomedicine. 2014; 10:473-482.

20. Lee YN, Kim MC, Lee YT, Wang HS, Cho MK, Lee JS, Ko EJ, Kang SM. AS04-adjuvanted virus-like particles containing multiple M2 extracellular domains of influenza virus confer improved protection. Vaccine. 2014; 32:4578-4585.

21. Zhang X, Liu M, Liu C, Du J, Shi W, Sun E, Li H, Li J, Zhang Y. Vaccination with different M2e epitope densities confers partial protection against $\mathrm{H} 5 \mathrm{~N} 1$ influenza A virus challenge in chickens. Intervirology. 2011; 54:290-299.

22. Zhou C, Zhou L, Chen YH. Immunization with high epitope density of M2e derived from 2009 pandemic. Vaccine. 2012; 30:3463-3469.

23. De Filette M, Min Jou W, Birkett A, Lyons K, Schultz B, Tonkyro A, Resch S, Fiers W. Universal influenza A vaccine: Optimization of M2-based constructs. Virology. 2005; 337:149-161.

24. Smith GJ, Vijaykrishna D, Bahl J. Lycett SJ, Worobey M, Pybus OG, Ma SK, Cheung CL, Raghwani J, Bhatt S, Peiris JS, Guan Y, Rambaut A. Origins and evolutionary genomics of the 2009 swine-origin H1N1 influenza A epidemic. Nature. 2009; 459:1122-1125.

25. Wu F, Huang JH, Yuan XY, Huang WS, Chen YH. Characterization of immunity induced by M2e of influenza virus. Vaccine, 2007; 25:8868-8873.

26. Kilbourne ED. Influenza pandemics of the 20th century. Emerg Infect Dis. 2006; 12:9-14.

27. Lee JS, Kwon YM, Wang HS, Lee YN, Ko EJ, Yoo SE, Kim MC, Kim KH, ChoMK, Lee YT, Lee YR, Quan FS, Kang SM. Baculovirus-expressed virus-like particle vaccine in combination with DNA encoding the fusion protein confers protection against respiratory syncytial virus. Vaccine. 2014; 32:5866-5874.

28. Kushnir N, Streatfield SJ, Yusibov V. Virus-like particles as a highly efficient vaccine platform: Diversity of targets and production systems and advances in clinical development. Vaccine. 2012; 17:58-83.

29. Kaminaka K, Matsuda J, Nozaki C. Influenza virus M2e with additional cysteine residues shows enhanced immunogenicity and protection against lethal virus challenge. Viral Immunol. 2013; 4:291-295.

(Received April 24, 2015; Revised July 27, 2015; Rerevised July August 24, 2015; Accepted August 24, 2015) 